\title{
PENGARUH METODE PEMBELAJARAN BAHASA KOMUNIKATIF (COMMUNICATIVE LANGUAGE TEACHING) TERHADAP KEMAHIRAN BERBAHASA ARAB
}

\author{
Yenni Yunita ${ }^{1}$, Rojja Pebrian' ${ }^{2}$ Ismail Akzam ${ }^{3}$ \\ Pendidikan Agama Islam Fakultas Agama Islam Universitas Islam Riau \\ e-mail : yenniyunita@fis.uir.ac.id, rojjapebrian@fis.uir.ac.id, akzamalbakanbaru@fis.uir.ac.id
}

\begin{abstract}
The communicative method is a method that relies more on students' creativities in doing exercises. At this stage, the direct roles of instructors/tutors are being reduced to provide opportunities for students to develop their own abilities. The students are emphasized to speak more than the instructors do. In the context of teaching Arabic at the Faculty of Islamic Studies of UIR, a language center institution called CELAD (Center For Languages and Academic Development) has been established as a means for teaching and developing foreign languages including Arabic which aims to make students understand Arabic both speaking and writing and able to apply it. The method used in this study is a quantitative method. In this study, the population consists of 327 students from four study programs of PAI, EKISY, PIAUD, PBS at FAI UIR. While the sample consists of 100 students. The conclusion of this study shows that: There is a significant influence of Communicative Language Teaching Method on students' Arabic proficiency in Language Classes (CELAD) of FAI-UIR.
\end{abstract}

Key words : Language Proficiency, Communicative Method, Language Learning

\begin{abstract}
ABSTRAK
Metode komunikatif adalah metode yang lebih mengandalkan kreativitas para pelajar dalam melakukan latihan. Pada tahap ini keterlibatan Instruktur/Tutor secara langsung mulai dikurangi untuk memberi kesempatan kepada mahasiswa untuk mengembangkan kemampuan sendiri. Para mahasiswa pada tahap ini ditekankan untuk lebih banyak berbicara dari pada Instruktur. Dalam konteks pengajaran bahasa Arab di Fakultas Agama Islam UIR telah berdiri lembaga pusat bahasa yang bernama CELAD (Center For Languages and Academic Development ) sebagai sarana untuk pengajaran dan pengembangan bahasa asing diantaranya bahasa Arab yang bertujuan agar mahasiswa mampu mamahami bahasa Arab baik secara lisan maupun tulisan serta mampu mengaplikasikannya. Adapun metode yang digunakan pada penelitian ini adalah dengan metode kuantitatif. Dalam penelitian ini yang dijadikan populasi adalah mahasiswa dari empat program studi PAI, EKISY, PIAUD, PBS FAI UIR yang berjumlah 327 orang. Sedangkan sampelnya berjumlah 100 orang. Kesimpulan dari penelitian ini menunjukkan bahwa: Terdapat pengaruh yang signifikan hasil dari Metode Pembelajaran Bahasa Komunikatif (Communicative Language Teaching) Terhadap Kemahiran Berbahasa Arab pada Mahasiswa Kelas Bahasa (CELAD) FAI-UIR.
\end{abstract}

Kata Kunci: Kemahiran Berbahasa, Metode Komunikatif, Pembelajaran Bahasa.

\begin{tabular}{|c|c|c|c|}
\hline FIRST RECEIVED: & REVISED: & ACCEPTED: & PUBLISHED: \\
29 June 2020 & 18 October 2020 & 31 October 2020 & 13 Desember 2020 \\
\hline
\end{tabular}




\section{PENDAHULUAN}

Bahasa Arab merupakan salah satu bahasa dunia yang telah mengalami perkembangan sosial masyarakat dan ilmu pengetahuan. Pembelajaran bahasa Arab dapat didefinisikan suatu upaya membelajarkan siswa untuk belajar bahasa Arab dengan guru sebagai fasilitator dengan mengorganisasikan berbagai unsur untuk memperoleh tujuan yang ingin dicapai.

Pada umumnya pengajaran bahasa Arab dimaksudkan untuk memberikan kepada peserta didik empat keterampilan dasar dalam berbahasa yang dianggap sebagai bentukbentuk dasar keterampilan bahasa dalam masyarakat yaitu: kemampuan membaca, menulis, berbicara dan mendengarkan. Dan untuk mencapainya diperlukan suatu metode yang tepat, di antaranya "metode komunikatif".

"Metode komunikatif adalah metode yang lebih mengandalkan kreativitas para pelajar dalam melakukan latihan. Pada tahap ini keterlibatan Instruktur/Tutor secara langsung mulai dikurangi untuk memberi kesempatan kepada mahasiswa untuk mengembangkan kemampuan sendiri. Para mahasiswa pada tahap ini ditekankan untuk lebih banyak berbicara dari pada Instruktur. Secara pikologis setiap kelas memiliki kecenderungan, pandangan dan kemampuan kolektif yang tidak sama, oleh sebab itu Instruktur harus pandai memanfaatkan kondisi ini agar setiap pembelajaran yang dilakukan setidaknya memberikan kegairahan kepada mereka."

Dalam konteks pengajaran bahasa Arab di Fakultas Agama Islam UIR telah berdiri lembaga pusat bahasa yang bernama
CELAD (Center For Languages and Academic Development ) sebagai saran untuk pengajaran dan pengembangan bahasa asing di antaranya bahasa Arab yang bertujuan agar mahasiswa mampu mamahami bahasa Arab baik secara lisan maupun tulisan serta mampu mengaplikasikannya. Agar tujuan ini tercapai maka diperlukan tenaga pengajar yang mampu menguasai atau menerapkan metode yg sesuai dengan kebutuhan peserta didik dan tuntutan lembaga khususnya terutama perguruan tinggi Islam.

Akan tetapi berdasarkan observasi yang penulis lakukan ada temuan yang menunjukkan bahwa "pelaksanaan metode yang dilakukan oleh tutor bahasa asing khususnya bahasa Arab di pusat bahasa CELAD Fakultas Agama Islam Universitas Islam Riau masih bersifat klasik dan tradisional sehingga pengajaran bahasa Arab terkesan kurang menyenangkan yang dirasakan oleh para mahasiswa/i yang mengambil kelas bahasa selama 1 (satu) tahun di semester 1 (satu) dan 2 (dua) bahkan tidak sedikit pula yang mengatakan pembelajaran bahasa Arab itu juga sulit untuk dipahami kemudian rendahnya minat mahasiswa dalam mempelajari bahasa Arab yang terlihat dari hasil evaluasi perolehan nilai baik lisan maupun tulisan yang dilaksanakan diakhir semester masih di bawah standar penilaian pusat bahasa CELAD. Hal ini menunjukkan bahwa tujuan pembelajaran bahasa Arab untuk menguasai 4 (empat) kemahiran berbahasa yaitu istima, qira'ah , kalam, dan kitabah masih jauh dari harapan." 


\section{METODE PENELITIAN}

Penelitian ini dilakukan di lembaga pusat bahasa CELAD ( Center for Language and Academic Development) Fakultas Agama Islam Universitas Islam Riau Pekanbaru. Pada penelitian ini yang menjadi populasi adalah mahasiswa yang mengikuti kelas bahasa CELAD terdiri dari empat program studi PAI, EKIS, PIAUD, dan PBSy yang berjumlah 327 orang. Sedangkan sampelnya berjumlah 100 orang. Untuk teknik pengumpulan data menggunakan observasi dan angket. Adapun
Metode yang digunakan pada penelitian ini adalah dengan metode kuantitatif.

\section{HASIL DAN PEMBAHASAN}

\section{Fungsi-fungsi Ungkapan Dalam Dialog}

Pendek

Dialog pendek disajikan dengan didahului penjelasan tentang fungsi-fungsi ungkapan dalam dialog itu dan situasi di mana dialog itu mungkin terjadi.

Tabel 1

Fungsi-fungsi Ungkapan Dalam Dialog Pendek

\begin{tabular}{|c|c|c|c|c|c|c|c|}
\hline \multirow{3}{*}{ No. } & \multirow{3}{*}{ Item Pernyataan } & \multicolumn{5}{|c|}{ Frekuensi Jawaban Responden } & \multirow{3}{*}{ Skor Total } \\
\hline & & SS & $\mathbf{S}$ & $\mathbf{N}$ & TS & STS & \\
\hline & & 5 & 4 & 3 & 2 & 1 & \\
\hline \multirow[t]{2}{*}{1.} & Anda dapat mengungkapkan & 13 & 59 & 16 & 7 & 5 & 100 \\
\hline & dialog pendek bahasa Arab & $13 \%$ & $59 \%$ & $16 \%$ & $7 \%$ & $5 \%$ & $100 \%$ \\
\hline \multirow[t]{3}{*}{2.} & Bahasa Arab itu sebagai & 54 & 40 & 3 & 1 & 2 & 100 \\
\hline & $\begin{array}{l}\text { instrumental untuk saling } \\
\text { mengenal Al-Qur'an dan Hadits }\end{array}$ & $54 \%$ & $40 \%$ & $3 \%$ & $1 \%$ & $2 \%$ & $100 \%$ \\
\hline & Total & 67 & 99 & 19 & 8 & 7 & \\
\hline
\end{tabular}

Data olahan: 2019

berdasarkan tabel di atas, jawaban responden pada item nomor 1 dominan menyatakan setuju sebanyak 59 responden atau (59\%), responden-responden tersebut setuju bahwa responden dapat mengungkapkan dialog pendek bahasa Arab.

\section{Kalimat-kalimat Pokok Bahasa Arab}

Pada item nomor 2 tentang pernyataan responden Bahasa Arab itu sebagai instrumental untuk saling mengenal AlQur'an dan Hadits, responden menyatakan sangat setuju yaitu ada 54 orang (54\%) dan responden yang menyatakan setuju ada 40 orang $(40 \%)$.

Tabel 2

Kalimat-kalimat Pokok Bahasa Arab

\begin{tabular}{|c|c|c|c|c|c|c|c|}
\hline \multirow{3}{*}{ No. } & \multirow{3}{*}{ Item Pernyataan } & \multicolumn{5}{|c|}{ Frekuensi Jawaban Responden } & \multirow{3}{*}{ Skor Total } \\
\hline & & SS & $\mathbf{S}$ & $\mathbf{N}$ & TS & STS & \\
\hline & & 5 & 4 & 3 & 2 & 1 & \\
\hline 1. & Anda mengenal Jumlah Ismiyyah & 10 & 44 & 26 & 14 & & 100 \\
\hline
\end{tabular}




\begin{tabular}{|c|c|c|c|c|c|c|c|}
\hline & & $10 \%$ & $44 \%$ & $26 \%$ & $14 \%$ & $6 \%$ & $100 \%$ \\
\hline \multirow[t]{2}{*}{2.} & Anda mengenal Jumlah Fi'liyyah & 11 & 49 & 23 & 14 & 3 & 100 \\
\hline & & $11 \%$ & $49 \%$ & $23 \%$ & $14 \%$ & $3 \%$ & $100 \%$ \\
\hline \multirow[t]{3}{*}{3.} & Anda menggunakan ta'bir-ta'bir & 7 & 31 & 39 & 17 & 6 & 100 \\
\hline & $\begin{array}{l}\text { bahasa Arab yang terdiri dari } \\
\text { satu, dua kata,dan tiga kata. }\end{array}$ & $7 \%$ & $31 \%$ & $39 \%$ & $17 \%$ & $6 \%$ & $100 \%$ \\
\hline & Total & 28 & 124 & 88 & 45 & 15 & \\
\hline
\end{tabular}

Berdasarkan tabel di atas, jawaban responden pada item nomor 1 dominan menyatakan setuju sebanyak 44 responden atau (44\%), responden-responden tersebut setuju bahwa responden dapat mengenal Jumlah Ismiyyah.

Pada item nomor 2 tentang pernyataan responden mengenal Jumlah Fi'liyyah, mayoritas responden menyatakan setuju yaitu ada 49 orang (49\%).

Pada item nomor 3 tentang pernyataan responden menggunakan ta'bir-ta'bir bahasa Arab yang terdiri dari satu, dua kata,dan tiga kata., mayoritas responden menyatakan netral yaitu ada 39 orang (39\%).

\section{Situasi Dialog Mahasiswa}

Tabel 3

Situasi Dialog Mahasiswa

\begin{tabular}{|c|c|c|c|c|c|c|c|}
\hline \multirow{3}{*}{ No. } & \multirow{3}{*}{ Item Pernyataan } & \multicolumn{5}{|c|}{ Frekuensi Jawaban Responden } & \multirow{3}{*}{ Skor Total } \\
\hline & & SS & $\mathbf{S}$ & $\mathbf{N}$ & TS & STS & \\
\hline & & 5 & 4 & 3 & 2 & 1 & \\
\hline \multirow[t]{2}{*}{1.} & Anda menggunakan bahasa Arab & 3 & 22 & 36 & 22 & 18 & 100 \\
\hline & $\begin{array}{l}\text { setiap berbicara kepada teman } \\
\text { Anda }\end{array}$ & $3 \%$ & $22 \%$ & $36 \%$ & $22 \%$ & $18 \%$ & $100 \%$ \\
\hline \multirow[t]{3}{*}{2.} & Anda menggunakan bahasa Arab & 8 & 58 & 21 & 10 & 3 & 100 \\
\hline & jika ditanya oleh tutor anda saja. & $8 \%$ & $58 \%$ & $21 \%$ & $10 \%$ & $3 \%$ & $100 \%$ \\
\hline & Total & 11 & 80 & 57 & 32 & 21 & \\
\hline
\end{tabular}

Data olahan: 2019

Berdasarkan tabel di atas, jawaban responden pada item nomor 1 dominan menyatakan netral sebanyak 36 responden atau (36\%), responden-responden tersebut nmenjawab netral bahwa responden menggunakan bahasa Arab setiap berbicara kepada teman.

Pada item nomor 2 tentang pernyataan responden menggunakan bahasa Arab jika ditanya oleh tutor anda saja, responden menyatakan setuju yaitu ada 58 orang (58\%). 


\section{Ungkapan Komunikatif dalam Dialog}

Tabel 4

Ungkapan Komunikatif dalam Dialog

\begin{tabular}{|c|c|c|c|c|c|c|c|}
\hline \multirow{3}{*}{ No. } & \multirow{3}{*}{ Item Pernyataan } & \multicolumn{5}{|c|}{ Frekuensi Jawaban Responden } & \multirow{3}{*}{ Skor Total } \\
\hline & & SS & $\mathbf{S}$ & $\mathbf{N}$ & TS & STS & \\
\hline & & 5 & 4 & 3 & 2 & 1 & \\
\hline \multirow[t]{2}{*}{1.} & Anda dapat berkomunikasi singkat & 12 & 41 & 30 & 12 & 5 & 100 \\
\hline & dengan bahasa Arab & $12 \%$ & $41 \%$ & $30 \%$ & $12 \%$ & $5 \%$ & $100 \%$ \\
\hline \multirow[t]{3}{*}{2.} & Anda dapat memahami ungkapan & 12 & 59 & 15 & 11 & 3 & 100 \\
\hline & komunikatif ungkapan sehari-hari & $12 \%$ & $59 \%$ & $15 \%$ & $11 \%$ & $3 \%$ & $100 \%$ \\
\hline & Total & 24 & 100 & 45 & 32 & 8 & \\
\hline
\end{tabular}

Data Olahan: 2019

Berdasarkan tabel di atas, jawaban responden pada item nomor 1 dominan menyatakan setuju sebanyak 41 responden atau 41\%), responden-responden tersebut menjawab netral bahwa responden dapat berkomunikasi singkat dengan bahasa Arab.

\section{Aturan tata Bahasa}

Tabel 5

Aturan Tata Bahasa Arab

\begin{tabular}{|c|c|c|c|c|c|c|c|c|}
\hline \multirow{3}{*}{ No. } & \multirow{3}{*}{\multicolumn{2}{|c|}{ Item Pernyataan }} & \multicolumn{5}{|c|}{ Frekuensi Jawaban Responden } & \multirow{3}{*}{ Skor Total } \\
\hline & & & SS & $\mathbf{S}$ & $\mathbf{N}$ & TS & STS & \\
\hline & & & 5 & 4 & 3 & 2 & 1 & \\
\hline \multirow[t]{2}{*}{1.} & Anda & dasar-dasar & 6 & 59 & 31 & 10 & 3 & 100 \\
\hline & nahu & & $6 \%$ & $59 \%$ & $31 \%$ & $10 \%$ & $3 \%$ & $100 \%$ \\
\hline \multirow[t]{2}{*}{2.} & Anda & dasar-dasar & 7 & 54 & 28 & 8 & 3 & 100 \\
\hline & saraf & & $7 \%$ & $54 \%$ & $28 \%$ & $8 \%$ & $3 \%$ & $100 \%$ \\
\hline \multirow[t]{3}{*}{3.} & \multirow{2}{*}{\multicolumn{2}{|c|}{$\begin{array}{l}\text { Anda dapat mengerti dalam } \\
\text { pemakaian mudzakkar dan } \\
\text { muannats }\end{array}$}} & 3 & 35 & 40 & 17 & 5 & 100 \\
\hline & & & $3 \%$ & $35 \%$ & $40 \%$ & $17 \%$ & $5 \%$ & $100 \%$ \\
\hline & \multicolumn{2}{|l|}{ Total } & 16 & 148 & 99 & 35 & 11 & \\
\hline
\end{tabular}

Data Olahan: 2019

Berdasarkan tabel di atas, jawaban responden pada item nomor 1 dominan menyatakan setuju sebanyak 59 responden atau (59\%), responden-responden tersebut
Pada item nomor 2 tentang pernyataan responden dapat memahami ungkapan komunikatif ungkapan sehari-hari, responden menyatakan setuju yaitu ada 59 orang (59\%). 
mayoritas responden menyatakan setuju yaitu ada 54 orang $(54 \%)$.

Pada item nomor 3 tentang pernyataan responden Anda dapat mengerti dalam pemakaian mudzakkar dan muannats, mayoritas responden menyatakan netral yaitu ada 40 orang (40\%).

\section{Praktik Dialog Komunikatif}

Tabel 6

Praktik Dialog Komunikatif

\begin{tabular}{|c|c|c|c|c|c|c|c|}
\hline \multirow{3}{*}{ No. } & \multirow{3}{*}{ Item Pernyataan } & \multicolumn{5}{|c|}{ Frekuensi Jawaban Responden } & \multirow{3}{*}{ Skor Total } \\
\hline & & SS & $\mathbf{S}$ & $\mathbf{N}$ & TS & STS & \\
\hline & & 5 & 4 & 3 & 2 & 1 & \\
\hline \multirow[t]{2}{*}{1.} & Anda menggunakan bahasa Arab & 5 & 44 & 33 & 11 & 7 & 100 \\
\hline & dengan teman anda. & $5 \%$ & $44 \%$ & $33 \%$ & $11 \%$ & $7 \%$ & $100 \%$ \\
\hline \multirow[t]{3}{*}{2.} & Anda lebih menguasai dialog & 4 & 20 & 42 & 21 & 13 & 100 \\
\hline & $\begin{array}{l}\text { setelah mengikuti kelas CELAD } \\
\text { FAI-UIR }\end{array}$ & $8 \%$ & $58 \%$ & $21 \%$ & $10 \%$ & $3 \%$ & $100 \%$ \\
\hline & Total & 9 & 62 & 75 & 32 & 20 & \\
\hline
\end{tabular}

Data Olahan: 2019

Berdasarkan tabel di atas, jawaban responden pada item nomor 1 dominan menyatakan setuju sebanyak 44 responden atau (44\%), responden-responden tersebut nmenjawab setuju bahwa responden

\section{Evaluasi Dialog Komunikatif}

Tabel 7

Evaluasi Dialog Komunikatif

\begin{tabular}{|c|c|c|c|c|c|c|c|}
\hline \multirow{3}{*}{ No. } & \multirow{3}{*}{ Item Pernyataan } & \multicolumn{5}{|c|}{ Frekuensi Jawaban Responden } & \multirow{3}{*}{ Skor Total } \\
\hline & & SS & $\mathbf{S}$ & $\mathbf{N}$ & TS & STS & \\
\hline & & 5 & 4 & 3 & 2 & 1 & \\
\hline \multirow[t]{2}{*}{1.} & Anda lancar dan fashih berbicara & 1 & 23 & 40 & 24 & 12 & 100 \\
\hline & bahasa Arab & $1 \%$ & $23 \%$ & $40 \%$ & $24 \%$ & $12 \%$ & $100 \%$ \\
\hline \multirow[t]{3}{*}{2.} & Anda selalu menggunakan bahasa & 8 & 45 & 22 & 14 & 11 & 100 \\
\hline & Arab dengan ungkapan pendek & $8 \%$ & $45 \%$ & $22 \%$ & $14 \%$ & $11 \%$ & $100 \%$ \\
\hline & Total & 9 & 68 & 62 & 38 & 23 & \\
\hline
\end{tabular}

\section{Data Olahan: 2019}

Berdasarkan tabel di atas, jawaban responden pada item nomor 1 dominan menyatakan netral sebanyak 40 responden atau $(40 \%)$, responden-responden tersebut menggunakan bahasa Arab dengan teman anda.

Pada item nomor 2 tentang pernyataan responden lebih menguasai dialog setelah mengikuti kelas CELAD FAI-UIR, responden menyatakan netral yaitu ada 44 orang (44\%) 
dengan ungkapan pendek, responden menyatakan setuju yaitu ada 45 orang (45\%).

\section{Kemahiran Menyimak}

Tabel 8

Kemahiran Menyimak

\begin{tabular}{|c|c|c|c|c|c|c|c|}
\hline \multirow{3}{*}{ No. } & \multirow{3}{*}{ Item Pernyataan } & \multicolumn{5}{|c|}{ Frekuensi Jawaban Responden } & \multirow{3}{*}{ Skor Tota } \\
\hline & & SS & $\mathbf{S}$ & $\mathbf{N}$ & TS & STS & \\
\hline & & 5 & 4 & 3 & 2 & 1 & \\
\hline \multirow[t]{2}{*}{1.} & Anda paham dengan apa yang & 1 & 23 & 40 & 24 & 12 & 100 \\
\hline & $\begin{array}{l}\text { dibicarakan dalam berbahasa } \\
\text { Arab }\end{array}$ & $1 \%$ & $23 \%$ & $40 \%$ & $24 \%$ & $12 \%$ & $100 \%$ \\
\hline \multirow[t]{2}{*}{2.} & Anda mendengarkan teman anda & 8 & 45 & 22 & 14 & 11 & 100 \\
\hline & $\begin{array}{l}\text { ketika berkomunikasi dalam } \\
\text { bahasa Arab }\end{array}$ & $8 \%$ & $45 \%$ & $22 \%$ & $14 \%$ & $11 \%$ & $100 \%$ \\
\hline \multirow[t]{3}{*}{3.} & Anda sering mendengarkan & 9 & 31 & 40 & 18 & 6 & 100 \\
\hline & $\begin{array}{l}\text { audio percakapan dalam bahasa } \\
\text { arab di media sosial. }\end{array}$ & $9 \%$ & $31 \%$ & $40 \%$ & $18 \%$ & $6 \%$ & $100 \%$ \\
\hline & Total & 18 & 99 & 102 & 56 & 29 & \\
\hline
\end{tabular}

Data Olahan: 2019

Berdasarkan tabel di atas, jawaban responden pada item nomor 1 dominan menyatakan netral sebanyak 40 responden atau (40\%), responden-responden tersebut netral bahwa responden paham dengan apa yang dibicarakan dalam berbahasa arab.

Pada item nomor 2 tentang pernyataan responden mendengarkan teman anda ketika berkomunikasi dalam bahasa arab, mayoritas responden menyatakan setuju yaitu ada 45 orang (45\%). Pada item nomor 3 tentang pernyataan responden sering mendengarkan audio percakapan dalam bahasa arab di media sosial, mayoritas responden menyatakan netral yaitu ada 40 orang (40\%).

\section{Kemahiran Membaca}

Tabel 9

Kemahiran Membaca

\begin{tabular}{|c|c|c|c|c|c|c|c|}
\hline \multirow{3}{*}{ No. } & \multirow{3}{*}{ Item Pernyataan } & \multicolumn{5}{|c|}{ Frekuensi Jawaban Responden } & \multirow{3}{*}{ Skor Total } \\
\hline & & SS & $\mathbf{S}$ & $\mathbf{N}$ & TS & STS & \\
\hline & & 5 & 4 & 3 & 2 & 1 & \\
\hline \multirow[t]{2}{*}{1.} & Anda mengerti dengan dialog dan & 5 & 31 & 40 & 18 & 6 & 100 \\
\hline & $\begin{array}{l}\text { latihan yang ada dalam buku } \\
\text { CELAD bahasa Arab }\end{array}$ & $5 \%$ & $31 \%$ & $40 \%$ & $18 \%$ & $6 \%$ & $100 \%$ \\
\hline \multirow[t]{3}{*}{2.} & mengulang & 10 & 59 & 20 & 8 & 3 & 100 \\
\hline & $\begin{array}{l}\text { membaca buku CELAD bahasa } \\
\text { arab }\end{array}$ & $10 \%$ & $59 \%$ & $20 \%$ & $8 \%$ & $3 \%$ & $100 \%$ \\
\hline & Total & 15 & 90 & 60 & 26 & 9 & \\
\hline
\end{tabular}


Berdasarkan tabel di atas, jawaban responden pada item nomor 1 dominan menyatakan netral sebanyak 40 responden atau $(40 \%)$, responden-responden tersebut menjawab setuju bahwa mengerti dengan dialog dan latihan yang ada dalam buku CELAD bahasa arab
Pada item nomor 2 tentang pernyataan responden sering mengulang membaca buku CELAD bahasa arab, responden menyatakan setuju yaitu ada 59 orang (59\%).

\section{Kemahiran Menulis}

Tabel 10

Kemahiran Menulis

\begin{tabular}{|c|c|c|c|c|c|c|c|}
\hline \multirow{3}{*}{ No. } & \multirow{3}{*}{ Item Pernyataan } & \multicolumn{5}{|c|}{ Frekuensi Jawaban Responden } & \multirow{3}{*}{ Skor Total } \\
\hline & & SS & $\mathbf{S}$ & $\mathbf{N}$ & TS & STS & \\
\hline & & 5 & 4 & 3 & 2 & 1 & \\
\hline \multirow[t]{2}{*}{1.} & Anda bisa menulis kata-kata arab & 7 & 30 & 45 & 11 & 7 & 100 \\
\hline & yang ada dalam buku CELAD & $7 \%$ & $30 \%$ & $45 \%$ & $11 \%$ & $7 \%$ & $100 \%$ \\
\hline \multirow[t]{2}{*}{2.} & Anda sering menulis tugas & 3 & 28 & 43 & 16 & 10 & 100 \\
\hline & $\begin{array}{l}\text { dalam berbahasa arab dengan } \\
\text { benar }\end{array}$ & $3 \%$ & $28 \%$ & $43 \%$ & $16 \%$ & $10 \%$ & $100 \%$ \\
\hline \multirow[t]{3}{*}{3.} & Anda ada menulis mufrodat & 4 & 22 & 44 & 17 & 13 & 100 \\
\hline & setiap belajar bahasa Arab & $4 \%$ & $22 \%$ & $44 \%$ & $17 \%$ & $13 \%$ & $100 \%$ \\
\hline & Total & 14 & 80 & 132 & 44 & 30 & \\
\hline
\end{tabular}

Data Olahan: 2019

Berdasarkan tabel di atas, jawaban responden pada item nomor 1 dominan menyatakan netral sebanyak 45 responden atau (45\%), responden-responden tersebut netral bahwa responden bisa menulis katakata arab yang ada dalam buku CELAD, dan responden yang menjawab setuju sebanyak 30 orang atau (30\%).
Pada item nomor 2 tentang pernyataan responden sering menulis tugas dalam berbahasa arab dengan benar, mayoritas responden menyatakan netral yaitu ada 43 orang $(43 \%)$. Pada item nomor 3 tentang pernyataan responden ada menulis mufradat setiap belajar bahasa arab, mayoritas responden menyatakan netral yaitu ada 44 orang (44\%).

\section{Kemahiran berbicara}


Tabel 11

Kemahiran berbicara

\begin{tabular}{|c|c|c|c|c|c|c|c|}
\hline \multirow{3}{*}{ No. } & \multirow{3}{*}{ Item Pernyataan } & \multicolumn{5}{|c|}{ Frekuensi Jawaban Responden } & \multirow{3}{*}{ Skor Total } \\
\hline & & SS & $\mathbf{S}$ & $\mathbf{N}$ & TS & STS & \\
\hline & & 5 & 4 & 3 & 2 & 1 & \\
\hline \multirow[t]{2}{*}{1.} & Anda bisa berbicara dengan & 2 & 33 & 38 & 14 & 13 & 100 \\
\hline & teman dalam berbahasa Arab & $2 \%$ & $33 \%$ & $38 \%$ & $14 \%$ & $13 \%$ & $100 \%$ \\
\hline \multirow[t]{2}{*}{2.} & Anda sering berbicara dalam & 8 & 43 & 36 & 7 & 6 & 100 \\
\hline & $\begin{array}{l}\text { bahasa arab ketika berjumpa } \\
\text { dengan teman }\end{array}$ & $8 \%$ & $43 \%$ & $36 \%$ & $7 \%$ & $6 \%$ & $100 \%$ \\
\hline \multirow[t]{3}{*}{3.} & Anda sering melatih diri sendiri & 3 & 20 & 46 & 18 & 13 & 100 \\
\hline & $\begin{array}{l}\text { dalam berbicara bahasa arab } \\
\text { dengan fasih }\end{array}$ & $3 \%$ & $20 \%$ & $46 \%$ & $18 \%$ & $13 \%$ & $100 \%$ \\
\hline & Total & 13 & 96 & 120 & 39 & 32 & \\
\hline
\end{tabular}

Data Olahan: 2019

Berdasarkan tabel di atas, jawaban responden pada item nomor 1 dominan menyatakan netral sebanyak 38 responden atau (38\%), responden-responden tersebut netral bahwa Anda bisa berbicara dengan teman dalam berbahasa arab, dan responden yang menjawab setuju sebanyak 33 orang atau $(33 \%)$.

Pada item nomor 2 tentang pernyataan responden sering berbicara dalam bahasa arab ketika berjumpa dengan teman, mayoritas responden menyatakan netral yaitu ada 43 orang $(43 \%)$. Pada item nomor 3 tentang pernyataan responden sering melatih diri sendiri dalam berbicara bahasa arab dengan fasih, mayoritas responden menyatakan netral yaitu ada 46 orang (46\%) dan responden yang menjawab setuju sebanyak 20 orang atau (20\%).

Adapun Hipotesis penelitian ini adalah sebagai berikut:

$\mathrm{H}_{0}$ : Tidak terdapat pengaruh metode pembelajaran bahasa komunikatif (communicative language teaching) terhadap kemahiran berbahasa Arab pada kelas bahasa (CELAD) mahasiswa FAI-UIR.

$\mathrm{H}_{\mathrm{a}}$ : Terdapat pengaruh antara pembelajaran bahasa komunikatif (communicative language teaching) terhadap kemahiran berbahasa Arab pada kelas bahasa (CELAD) mahasiswa FAIUIR.

Dengan cronbach alpha $\alpha 0,05$ dan kriteria sebagai berikut:

Signifikansi $>\alpha=0,05$, maka $\mathrm{H}_{0}$ diterima dan $\mathrm{H}_{\mathrm{a}}$ ditolak

Signifikansi $<\alpha=0,05$, maka $\mathrm{H}_{0}$ ditolak dan $\mathrm{H}_{\mathrm{a}}$ diterima

Berdasarkan output data dengan bantuan SPSS versi 23 diperoleh nilai signifikansi sebesar 0.000, kriteria pengujian: $0,000<$ $\alpha=0,05$, maka $\mathrm{H}_{0}$ ditolak dan $\mathrm{H}_{\mathrm{a}}$ diterima.

Jika $\mathrm{t}$ hitung $<\mathrm{t}$ tabel, maka $\mathrm{H}_{0}$ diterima dan $\mathrm{H}_{\mathrm{a}}$ ditolak

Jika $\mathrm{t}$ hitung $>\mathrm{t}$ tabel, maka $\mathrm{H}_{0}$ ditolak dan $\mathrm{H}_{\mathrm{a}}$ diterima

$\mathrm{t}$ tabel $=\mathrm{n}-\mathrm{k}-1:$ alpha/2 


$$
\begin{aligned}
& =100-1-1: 0,05 / 2 \\
& =98: 0,025 \\
& =3,920
\end{aligned}
$$

$\mathrm{t}$ hitung $(13,799)>\mathrm{t}$ tabel $(1,480)$, maka $\mathrm{H}_{0}$ ditolak dan $\mathrm{H}_{\mathrm{a}}$ diterima

Berdasarkan hasil pembahasan di atas, dapat dibuktikan bahwa hipotesis alternatif dapat diterima karena metode pembelajaran bahasa komunikatif (Communicative Language Teaching) berpengaruh signifikan terhadap kemahiran berbahasa Arab mahasiswa pada kelas (CELAD) FAI UIR. Hal ini terbukti dengan diketahui Sig. $(0,000)>0,05$ dan nilai $\mathrm{t}$ hitung $(13,799)>\mathrm{t}$ tabel $(1,480)$. Artinya ada pengaruh antara pembelajaran bahasa komunikatif (communicative language teaching) terhadap kemahiran berbahasa Arab pada kelas bahasa (CELAD) mahasiswa FAIUIR.

\section{SIMPULAN}

Terdapat pengaruh antara metode pembelajaran bahasa komunikatif (Communicative Language Teaching) terhadap kemahiran berbahasa Arab pada kelas bahasa (CELAD) mahasiswa FAI-UIR. Dengan dibuktikan bahwa "Hipotesis alternatif dapat diterima karena komunikasi interpersonal Tutor berpengaruh signifikan dalam meningkatkan kemahiran berbahasa pada kelas bahasa (CELAD) mahasiswa FAIUIR." Hal ini terbukti dengan diketahui Sig. $(0,000)>0,05$ dan nilai $t$ hitung $(13,799)>t$ tabel (1,480). Kemudian Uji koefisien determinasi (r2) dilakukan untuk mengukur seberapa besar persentase pengaruh antara pembelajaran bahasa komunikatif (Communicative Language Teaching) terhadap kemahiran berbahasa Arab pada kelas bahasa (CELAD) mahasiswa FAI-UIR. Diketahui nilai $\mathrm{R}$ square sebesar 0,660. Artinya sumbangan pengaruh antara Metode pembelajaran bahasa komunikatif (Communicative Language Teaching) terhadap kemahiran berbahasa Arab pada kelas bahasa (CELAD) mahasiswa FAI-UIR.

\section{DAFTAR PUSTAKA}

Arsyad, A. (2003). Bahasa Arab dan Metode Pengajarannya. Surabaya: Pustaka Pelajar.

Effendy, A. F. (2009). Metodologi Pengajaran Bahasa Arab. Malang: Misykat.

Gani, B. A. (1987). Al Arabiyah BinNamadzij. Jakarta: PT. Bulan Bintang.

Hamid, M., \& Fatimah, S. (2002). Development of Arabic Conversation Material Based on CommunicativeInteractive Approach. Journal of Arabic Learning, 46-63.

Hamzah. (2008). Perencanaan pembelajaran. Jakarta: Bumi Aksara.

Hermawan, A. (2011). Metode Pembelajaran. Bandung: PT. Remaja Rosda Karya.

Hermawan, A. (2011). Metodologi Pembelajaran Bahasa Arab. Bandung: PT. Remaja Rosda Karya.

Ismail, Z. Pendidikan, F., Malaya, U., Tamuri, A. H., Mohd, N., Nik, R., Ashinida Aladdin Afendi Hamat, M. S. Y. (2011). Pengajaran Bahasa Arab Sekolah Menengah. GEMA Online Journal of Language Studies, 11, 67-82.

Makinuddin, M. (2017). Metode Pengajaran Bahasa. MIYAH, Jurnal Studi Islam.

Mawanti, D.(2019). needs analysis of the islamic arabic material teaching based on 
communiative for university students. jurnal pendidikan Islam, 253-274.

Rosyidi, A. W., \& Ni'mah, M. (2011). Memahami konsep dasar pembelajaran bahasa arab. Malang: UIN-Maliki Press.

Wahab, A. (2015). Metode Pembelajaran Bahasa Arab. Jurnal Pendidikan Bahasa Arab.

Zainudin, R. (2005). Pembelajaran Bahasa Arab. Jakarta: Pustaka Rihlah Group. 